historic events that such opinions are often so widely divergent.

The volume is divided into three parts: from 1,200 to 500 B.C., thence to the Christian Era, thence to A.D. 500. Each part is treated in similar vein, beginning with historical events, and followed by language, technology, organization, religion and literature with their related topics. From some aspects this arrangement is to be disputed, apart from the artificial separation of such subjects as politics and economy, because it is difficult to trace the cultural and scientific developments in any one chosen area. Certain aspects of certain areas cannot be considered, and America and the Pacific are badly neglected, but perhaps inevitably when they must compete with Greece and Roman Italy, from where much of the evidence treated here has been derived.

The aim of the volume is to present a general impression of the development of technology, political organization, religion and so on, over widespread areas. As a result, the facts that can be given to describe a specific situation in a certain region cannot be more than an abbreviated summary, and will not be of much use to one who is looking for basic factual material, although an extensive bibliography of Greek, Roman and Near Eastern literature is provided. Nevertheless, it is of the greatest interest and value to have certain aspects of cultural development brought together from different areas for comparison; the emergence and dispersal of Indo-European languages is reasonably well known, if not agreed on, but less so the complex evolution of writing systems. Of particular interest, too, may be the evidence presented here for the discovery of scientific principles and allied philosophies.

In my opinion, the volume falls between two stools; on one hand, the purely objective and factual presentation with full bibliographical references; on the other, the theory of devclopmental processes throughout the world. The book scarcely aims as high as the first, and the nature of its production, with many differing opinions and editorial comments added, interrupts the flow essential to the second. Nevertheless, it probably comes as close as any book could to success in both fields.

J. M. Coles

\section{SOIL FABRICS}

Fabric and Mineral Analysis of Soils

By Dr. Roy Brewer. Pp. xiii +470. (New York and London: John Wiley and Sons, Inc., 1964.) $113 s$.

COILS are identified and classified to a great extent by D characters which are essentially morphological and can be observed in the field. The most important morphological characteristic is of course the division of the soil profile into horizons. Field observations of soil morphology even when supplemented by physical and chemical analyses do not, however, permit a sufficiently detailed and certain explanation of the processes involved in soil formation.

The need for a more precise analytical approach to pedology is expressed in the introduction to this book. Dr. Brewer directs attention to the soil material rather than the soil profile as the unit of study. The purpose of the book is to provide a system of description and classification of the phenomena observed in soils and to demonstrate the application of mineral analysis to studies of soil genesis.

Mineral analysis, dealt with in the first section of the book, is presented with an intentional geological bias and much of the information relating to mineral grains, for example the analysis of size and shape, can be found in standard text-books of sedimentary petrology.

Calculations of soil formation are discussed, with em. phasis on the use of a stable mineral to estimate gains and losses of weight and volume and of a particular constituent during soil formation. The equations proposed to calculate these changes in the soil profile seem unnecessarily complicated and could easily be worked out from first principles. The author argues convincingly in favour of using parent rock selected on the basis of mineral analysis of the profile as the parent material for evaluating profile development. There is no doubt that the present arbitrary recognition of weathered rock as parent material leads to serious errors.

The subject of mineral stability and weathering is examined on a somewhat empirical basis. Considering the significance of plasma in soil fabrics, it is a pity that the relations between mineral stability and atomic structure were not explored further. One surprising error in this chapter is the assertion that "the rate of weathering of mineral grains is directly related to surface area of the grains, that is, inversely related to size of grains" (p. 74). Specific surface must of course be intended. A chapter on the classification of rocks as the parent materials of soils, completing the section on mineral analysis, is of limited value and in some particulars inaccurate.

The valuable section of this book, making up more than three-quarters of the whole, deals with the structure and fabric analysis of soils with special emphasis on the description, classification and, to some extent, the interpretation of pedological features. Most of the phenomena described are best seen in thin section and they are particularly well illustrated with more than one hundred photomicrographs.

Much of the recent research in this field has been promoted by Dr. Brewer and his colleagues at the Soils Division, C.S.I.R.O., Australia. It is not surprising to find that this section is very largely based on their work and that several important papers have been included with little amendment. As the question might arise as to whether specialists would be prepared to pay over $£ 5$ for the convenience of having these papers in book form it is only fair to add that they make up only about one-quarter of the section.

The concepts of structure and fabric are clearly discussed with new definitions proposed for terms in common, but sometimes vague, use among pedologists. The following new definition of soil structure is essentially the theme of the book: "Soil structure. The physical constitution of a soil material as expressed by the size, shape and arrangement of the solid particles and voids, including both the primary particles to form compound particles and the compound particles themselves; fabric is the element of structure which deals with arrangement".

The main components of soil structure, voids, pedological features such as cutans and crystallaria, the soil matrix and peds are clearly described and carefully classified.

It is worth mentioning the author's proposal that the term 'ped' be restricted to those aggregates entirely enclosed by natural surfaces. Peds are thus recognized by their surface characters rather than by the mere presence of a population of units of similar size and shape. Most ficld workers would probably support this suggestion.

A chapter is devoted to a discussion of the role of fabric and mineral analysis in soil science followed by an appendix describing the techniques involved.

This book does not, as suggested on the publishers' jacket, provide a thorough understanding of soil genesis and this could not have been the author's intention. It cannot be recommended, therefore, to students with only a general interest in soil science. The book is the most comprehensive treatment of soil fabric analysis at present available and, with the reservations expressed here, it will be welcomed by pedologists. The fact that the soil fabric must be significant in soil/plant relationships will mean that reference to this work will benefit research workers in a much wider field. The book is well bound and printed.
J. L. M. LAMBert 